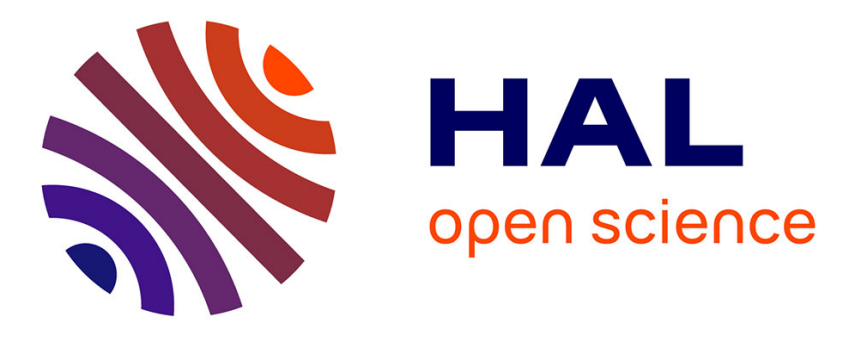

\title{
Experimental analysis of water-based nanofluids using boron nitride nanotubes with improved thermal properties
}

Roberto Gomez-Villarejo, Teresa Aguilar, Samah Hamze, Patrice Estellé, Javier Navas

\section{To cite this version:}

Roberto Gomez-Villarejo, Teresa Aguilar, Samah Hamze, Patrice Estellé, Javier Navas. Experimental analysis of water-based nanofluids using boron nitride nanotubes with improved thermal properties. Journal of Molecular Liquids, 2019, 277, pp.93-103. 10.1016/j.molliq.2018.12.093 . hal-02086544

HAL Id: hal-02086544

https://hal-univ-rennes1.archives-ouvertes.fr/hal-02086544

Submitted on 12 Apr 2019

HAL is a multi-disciplinary open access archive for the deposit and dissemination of scientific research documents, whether they are published or not. The documents may come from teaching and research institutions in France or abroad, or from public or private research centers.
L'archive ouverte pluridisciplinaire HAL, est destinée au dépôt et à la diffusion de documents scientifiques de niveau recherche, publiés ou non, émanant des établissements d'enseignement et de recherche français ou étrangers, des laboratoires publics ou privés. 


\section{Experimental analysis of water-based nanofluids using boron} nitride nanotubes with improved thermal properties

Roberto Gómez-Villarejo, ${ }^{1}$ Teresa Aguilar, ${ }^{1}$ Samah Hamze ${ }^{2}$, Patrice Estellé, ${ }^{2}$ Javier Navas, ${ }^{1, *}$

\footnotetext{
${ }^{1}$ Departamento de Química Física, Facultad de Ciencias, Universidad de Cádiz, E-11510 Puerto Real (Cádiz), Spain;

${ }^{2}$ Univ Rennes, LGCGM, EA3913, F-35000 Rennes, France
}

*Corresponding author: J. Navas (javier.navas@uca.es) 


\begin{abstract}
Nowadays, the use of nanofluids as alternative to commonly-used industrial heat transfer fluids is a topic of increasing interest. Analysing the improved efficiency of heat transfer processes according to advanced nanomaterials and obtaining stable nanofluids is one of the most interesting challenges. This paper presents a study of nanofluids based on boron nitride nanotubes and using an aqueous solution of Triton X100 (which acts as a surfactant) as the base fluid. UV-vis spectroscopy, particle size measurements (size between $150-170 \mathrm{~nm}$ ) and $\zeta$ potential (at about $-25 \mathrm{mV}$ ) showed that stable nanofluids were obtained. Surface tension measurements were also performed. The surface tension of water was weakly affected by the presence of any amount of nanoparticles and was mainly governed by the presence of surfactant. The rheological properties of the fluids were also analysed, as were their isobaric specific heat and thermal conductivity values. A Newtonian behaviour was observed for the base fluid and the nanofluids, with no significant increase in viscosity. The isobaric specific heat increased by $8 \%$ and thermal conductivity by $10 \%$ compared with the base fluid. Thus, the results obtained are interesting because while thermal properties improved with nanoparticle content, rheological behaviour did not change. Consequently, the nanofluids studied in the current paper do not raise the pressure drop and pumping power significantly and may therefore be a good option for thermal system applications.
\end{abstract}

Keywords: Heat transfer; Nanofluids; Boron nitride nanotubes; Thermal conductivity; rheological properties. 


\section{Introduction}

Nanofluids are systems based on nano-sized materials suspended in a fluid[1]. They have been the subject of numerous scientific studies in recent years in the form of experiments, theoretical developments and numerical simulations [2, 3]. Such a great effort is a result of nanofluids possessing enhanced properties that are of interest for applications such as engine cooling[4], electronic device cooling[5], concentrating solar energy[6], nuclear reactors[7], high voltage transformers[8], etc. The most interesting properties are their high isobaric specific heat[9] and thermal conductivity[1] values. Furthermore, the analysis of their rheological properties is of great interest in many applications involving fluid flow. For example, Heris et al. [10] reported the rheological behaviour of $\mathrm{ZnO}$-based nanofluids as lubricants, and also Yiamsawas et al. [11] reported the analysis of nanofluids based on $\mathrm{Al}_{2} \mathrm{O}_{3}$ and $\mathrm{TiO}_{2}$ for high temperature applications. Thus, numerous studies in recent decades have analysed the enhancement of the thermal properties of the typical heat transfer fluids used, such as water[12, 13], ethylene glycol[12, 14] or a mixture of both [15]. For example, Gao et al. [12] reported increases in thermal conductivity of up to $4.6 \%, 18 \%$, and $6.8 \%$ using graphene nanoplatelets in ethylene glycol, a 1:1 mixture of deionized water and ethylene glycol and deionized water, respectively. In addition, metal oxide $[6,11,16-18]$ and metallic nanoparticles $[19,20]$ have been widely analysed for suspension in the base fluid. Yasinskiy et al. [6] reported an increase in thermal conductivity of up to $25.8 \%$ for $\mathrm{TiO}_{2}$-based nanofluids. In addition, enhancements have been reported of up to $6 \%$ and $13 \%$ for $\mathrm{Ag}$ and $\mathrm{Cu}$-based nanofluids using a heat transfer fluid typically used in Concentrating Solar Power [19, 20]. Nowadays, advanced nanomaterials are being used in nanofluid technology. In this sense, the use of boron nitride could be of interest. 
The discovery of a new mono-dimensional material based on boron nitride structures and known as boron nitride whiskers was reported in 1981 by Ishii [21]. However, perfect tubular boron nitride structures were not synthesized until 1995 using an arcdischarge technique [22]. The next main challenge was the synthesis and characterization of boron nitride nanotubes. To this effect, many methods were invented or modified: laser ablation [23], chemical vapour deposition (CVD) [24] or substitution reactions [25]. In turn, applications such as polymeric and ceramic composites [26] or hydrogen storage [27] have been reported. Currently, boron nitride is known as "white graphene" [28, 29] and can be found in numerous shapes, including spheres [30], tubes [31] or ribbons [32]. Since it has similar structures and properties to carbon-based materials, predictably, the two have often been compared, in particular carbon nanotubes (CNTs) and boron nitride nanotubes (BNNTs). Both BNNTs and CNTs have similar mechanical properties and great thermal stability, meaning both can be applied to improve the thermal conductivity of matrix materials or fluids. The main difference between the two tube types is that CNTs are excellent electrical conductors that are normally used to improve the electrical conductivity of polymers [33, 34]. Meanwhile, BNNTS are basically electrically insulators and are appealing insulating materials with high thermal conductivity [35]. $\mathrm{BN}$ is also a highly stable dielectric ceramic material and interesting behaviour has been reported related to the electric and magnetic properties of nanofluids based on BN [36-38].

In this study, nanofluids based on BNNTs were prepared and characterized. An aqueous solution of Triton X-100, which acts as the surfactant, was used as the base fluid. The stability of the nanofluids was analysed by means of UV-vis spectroscopy, and particle size and $\zeta$ potential measurements. The surface tension and rheological properties of the fluids were also measured and analysed according to the temperature and concentration 
of BNNTs. Finally, thermal properties, such as isobaric specific heat and thermal conductivity were measured and also analysed with regard to the concentration of BNNTs and temperature.

\section{Materials and Methods}

\subsection{Nanofluid preparation}

Reagents. Triton X-100 and boron nitride nanotubes (BNNTs) were purchased from Sigma Aldrich (Saint-Quentin-Fallavier; France). Triton $\mathrm{X}-100\left(\mathrm{C}_{14} \mathrm{H}_{22} \mathrm{O}\left(\mathrm{C}_{2} \mathrm{H}_{4} \mathrm{O}\right)_{\mathrm{n}}\right)$ is a non-ionic surfactant that has a hydrophilic polyethylene oxide chain and an aromatic hydrocarbon lipophilic or hydrophobic group. It is available in liquid form and has average molecular weight of 625 and a density of $1.07 \mathrm{~g} / \mathrm{cm}^{3}$.

As indicated by manufacturer data [39], BNNTs content is higher than $50 \%$ and elemental B free lower than $25 \%$. The average nanotube diameter is about $5 \pm 2 \mathrm{~nm}$. Surface area (BET) of BNNTs is higher $100 \mathrm{~m}^{2} / \mathrm{g}$. It should also be noted that the BNNTs presently used are produced from inductively coupled plasma synthesis without metal catalysis [39]. In the absence of a density value for BNNTs in the manufacturer's specification, it was measured by gas pycnometry as explained the in following section. Preparation. Nanofluids were prepared following the two-step method [40] whereby the nanomaterial is first synthesized and then dispersed in a base fluid. In this study, boron nitride nanotubes were used as the nanomaterial. The base fluid used was a 0.35 vol\% aqueous solution of Triton X-100, which was used as stabilizing agent. Five nanofluids were prepared with different concentrations of BNNTS in the base fluid: $0.1 \cdot 10^{-2}, 0.3$. $10^{-2}, 0.5 \cdot 10^{-2}, 1.0 \cdot 10^{-2}, 3.0 \cdot 10^{-2} \mathrm{wt} \%$. In each case, the amount of Triton X-100 for 0.35 vol\% solution was mixed in water $(100 \mathrm{~mL})$ under magnetic stirring for 30 minutes. Then, BNNTs were added to the solution in the right amounts to obtain the 
concentrations given above. The nanofluids were kept in a sonication bath $(80 \mathrm{~Hz}$, Elmasonic P by Elma ${ }^{\circledR}$ ) for 2 hours at a temperature below $30^{\circ} \mathrm{C}$. Moreover, a solution of the base fluid, Triton X-100 with the same concentration noted before, was prepared for comparison purposes.

\subsection{Nanomaterial characterization}

The BNNTs were characterized by Scanning Electron Microscopy (SEM) and X-Ray Diffraction (XRD). The SEM of the BNNTs was performed with a JEOL-JSM-7100F microscope. Samples were prepared by depositing the nanoparticles on a carbon substrate. The images were taken at an accelerating voltage of $5 \mathrm{kV}$ and magnifications in the 20000 - 50000 range. Powder XRD experiments were performed on the BNNTs at room conditions with a Bruker D8 Advance diffractometer working in a $\theta-2 \theta$ modified Bragg-Brentano geometry and equipped with a LynxEye fast detector. The $\mathrm{Cu}$ K $\alpha 1$ radiation $(\lambda=1.5406 \AA$ ) was selected using a Ge(111) monochromator and the $2 \theta$ angular domain was scanned with a step size of $0.0197^{\circ}$ and integration time of $179 \mathrm{~ms}$ per step. A misoriented single crystalline Si sample holder was used to prevent any background signal from it. Samples were prepared from the deposition of the BNNTs that were dispersed in the Si sample holder with ethanol then dried in air before the XRD experiments.

Finally, the true density of the BNNTs was measured using an Ultrapic 1200e gas pycnometer (Quantachrome Instruments, USA) using nitrogen. The experiments were performed in replicate at room temperature with two different sample masses, which were carefully weighed with a precision balance. For each replicate, density was the average of 6 measurements. 


\subsection{Nanofluid characterization}

The nanofluids prepared were characterized for both stability and efficiency for comparison with the base fluid.

The improved efficiency of nanofluids results from significantly enhancing their thermal properties. However, this efficiency also depends on their stability. Thus, several techniques were used to analyse the chemical and physical stability of the nanofluids over time. UV-Vis spectroscopy makes it possible to assess the sedimentation process and therefore the stability of the nanofluids [41]. To this end, $\mathrm{UV}-\mathrm{V}$ is spectra were recorded in the wavelength range from 350 to $880 \mathrm{~nm}$ to analyse the presence of BNNTs in suspension. The system used consisted of a DH-2000-BAL halogen supplied by Ocean Optics@ (Ocean Optics, United Kingdom) as the light source, and a USB200+ spectrometer supplied by Ocean Optics@. The particle size and size distribution were measured by dynamic light scattering (DLS), a common technique for analysing colloidal systems [16, 42]. Furthermore, $\zeta$ potential measurements were performed to evaluate and understand the interactions between the particles in suspension and therefore the agglomeration process. A zetasizer Nano ZS system supplied by Malvern $@$ (Malvern, United Kingdom) was used to perform both measurements. The UV-vis spectra, and particle size and $\zeta$ potential measurements were performed for 25-30 days, recording several measurements each day.

The efficiency of the nanofluids can also be evaluated from the heat transfer coefficient, which depends on all their thermophysical properties, such as thermal conductivity, density, isobaric specific heat, dynamic viscosity and surface tension [43]. Consequently, the nanofluids were characterized for these properties.

The surface tension (ST) of the nanofluids was measured because this property plays an important role in many heat transfer processes and configurations, as recently 
emphasized by Estellé et al. [44]. This paper also reported that in most cases a decrease in surface tension leads to an increase in heat transfer properties. Thus, surface tension was measured at the interface between air and both the base fluid and nanofluids in the 10-50 ${ }^{\circ} \mathrm{C}$ temperature range with a DSA-30 Drop Shape Analyzer from KRÜSS GmBH (Hamburg, Germany) based on the pendant drop technique. Temperature regulation within temperature chamber was achieved using a Peltier system and the temperature was monitored with a PT100 probe inserted into the temperature chamber. The experimental equipment is described in Figure 1a. Measurements at room condition were also performed and compared to the measurements under controlled conditions.

The experimental procedure consists of using a 15-gauge needle with an outer diameter of $1.835 \mathrm{~mm}$ to produce drops with controlled flow rate and volume, as reported previously [45]. Then, the instrument records and digitally analyses the shape of the sample drops formed at the end of a syringe just at the moment when the drop snaps from the apex of the needle. Finally, surface tension is obtained from a drop shape analysis through a balance of internal and external forces acting on the drop and based on the Young-Laplace equation, as shown in Figure 1b. Thus, the reported ST values are the average of at least 10 measurements and no observable deviation between measurements was shown from the replicates. The needle remains within the chamber at least 10 mins at the required temperature before producing the drop. 

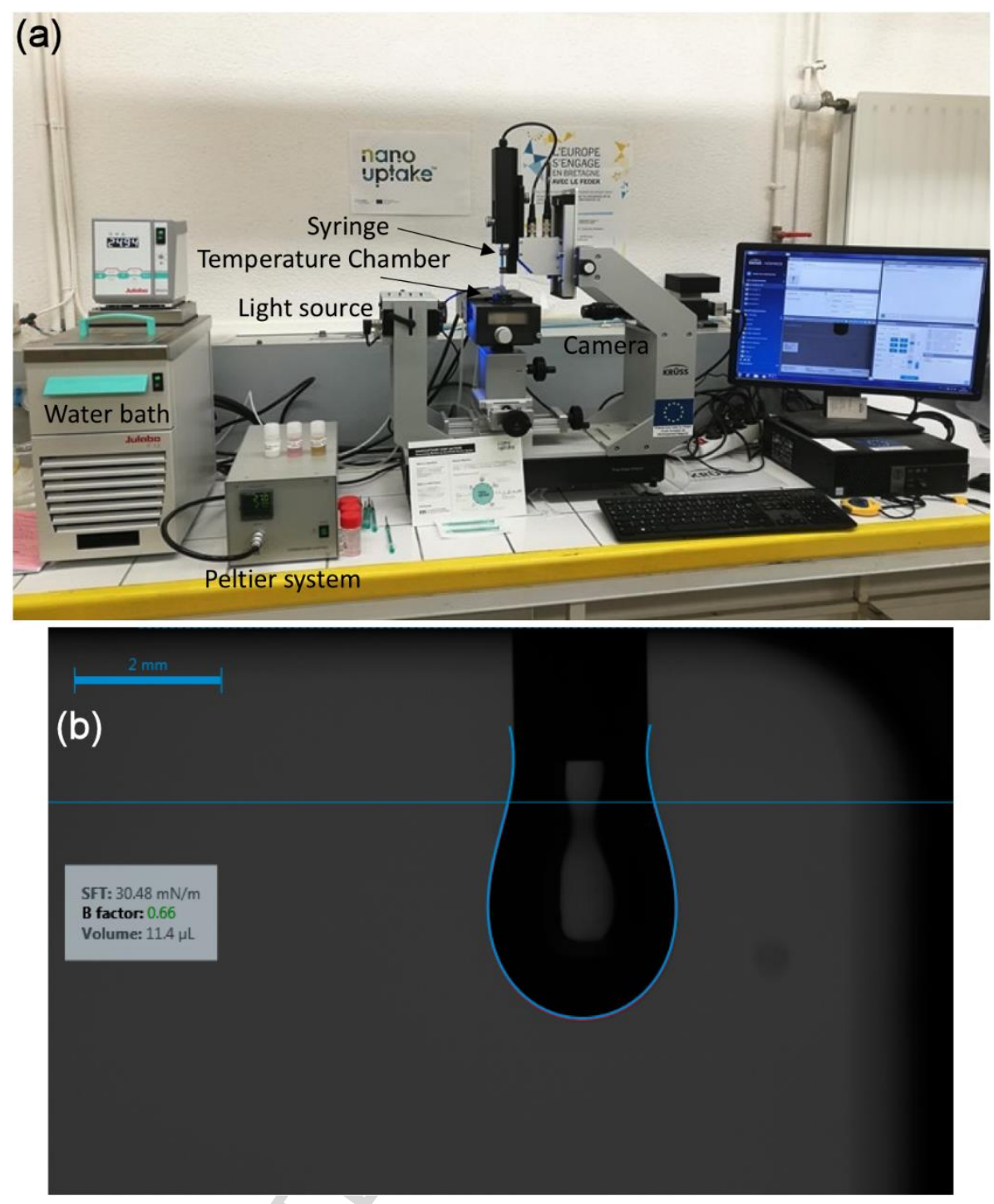

Figure 1. (a) Experimental equipment for ST measurements, and (b) example of pendant drop image of nanofluid with 0.005 in wt. $\%$ at $40^{\circ} \mathrm{C}$.

Rheological measurements were performed with a Kinexus Pro stress-controlled rheometer from Malvern Instruments Ltd (Malvern, United Kingdom) equipped with a cone and plate geometry. Due to the low viscosity of the nanofluids, a cone with an angle of $1^{\circ}$ and diameter of $60 \mathrm{~mm}$ was used. Measurements were performed under steady-state conditions imposing a logarithmic shear stress ramp which was selected to cover a shear rate range from around 10 to $1000 \mathrm{~s}^{-1}$ for each sample. Before measurement, the sample was carefully transferred to the lower plate then covered with 
the upper cone with a gap of $0.03 \mathrm{~mm}$, linked to cone geometry and dimension. Next, was left at the required temperature for $5 \mathrm{~min}$ before starting the experiment, allowing the whole sample volume to reach the temperature. It should be noted that temperature was imposed and controlled with a Peltier temperature control device located under the lower plate with a precision of $\pm 0.1^{\circ} \mathrm{C}$. In addition, thermal clovers were also placed around the testing geometry. The experiments were performed between 10 and $50{ }^{\circ} \mathrm{C}$ and the number of points per decades was adjusted to avoid sample evaporation at the geometry edge during measurement. Evaporation cannot be controlled at temperatures higher than $50{ }^{\circ} \mathrm{C}$. Additional information about this measurement procedure and uncertainty evaluation in viscosity measurement, reported to be less than $4 \%$, can be found in [46]. Water alone, the base fluid (aqueous solution of Triton X-100) and all the nanofluid samples were tested to verify the uncertainty in viscosity measurement, evaluate the influence of the surfactant on water viscosity and the effect of nanoparticle content respectively. Finally, the experiments were performed in two or three replicates with no observable differences.

In turn, thermal properties such as isobaric specific heat and thermal conductivity were measured to analyse the efficiency of the nanofluids prepared. The isobaric specific heat measurements were performed using a temperature modulated differential scanning calorimeter (TMDSC), model DSC214 Polyma, supplied by Netzsch@ (Netzsch, Germany). To perform the measurements, a program was created that can be summed up as: the temperature was equilibrated at $341 \mathrm{~K}$ to remove contaminants and kept isothermal for 10 minutes; then the samples were equilibrated at $288 \mathrm{~K}$ and then ramped to $373 \mathrm{~K}$ at a rate of $1 \mathrm{~K} / \mathrm{min}$. A modulation was programmed around the studied temperatures with an amplitude of $\pm 1 \mathrm{~K}$ and a period of 120 s. Finally, cooling was performed at $1 \mathrm{~K} / \mathrm{min}$. The isobaric specific heat of the base fluid was measured for 
comparison purposes. Moreover, thermal conductivity was measured by the laser flash technique (LFA) using LFA467 HyperFlash technology supplied by Netzsch@ (Netzsch, Germany). To be precise, this technique measures thermal diffusivity, a thermophysical property that defines the speed of heat propagation by conduction during changes of temperature, or how quickly a material reacts to a change in temperature. According to Standard ASTM E 1461-01, thermal conductivity may be calculated by the equation:

$$
k(T)=D(T) \cdot C_{P}(T) \cdot \rho(T)
$$

where $k$ is the thermal conductivity, $D$ is the thermal diffusivity, $C_{P}$ is the isobaric specific heat and $\rho$ is the density.

\section{Results and discussion}

\subsection{Nanomaterial characterization}

The BNNTs used to prepare the nanofluids were characterized to determine their intrinsic properties by means of techniques such as SEM, XRD and density measurements. Figure $2 \mathrm{a}$ shows the growth direction parallel to the BNNT fibrils. At increased magnification, Figures $2 \mathrm{~b}$ and $2 \mathrm{c}$ show that the BNNTs appear predominantly in bundles rather than individually and that these bundles mainly form an entangled network. Figure $2 \mathrm{c}$ shows that the diameter of the BNNT bundles is about $30 \mathrm{~nm}$. This is larger than the average nanotube diameter expected and reported by the manufacturer. It can also be observed that some impurities, such as spherical particles, are present in the BN sample. 


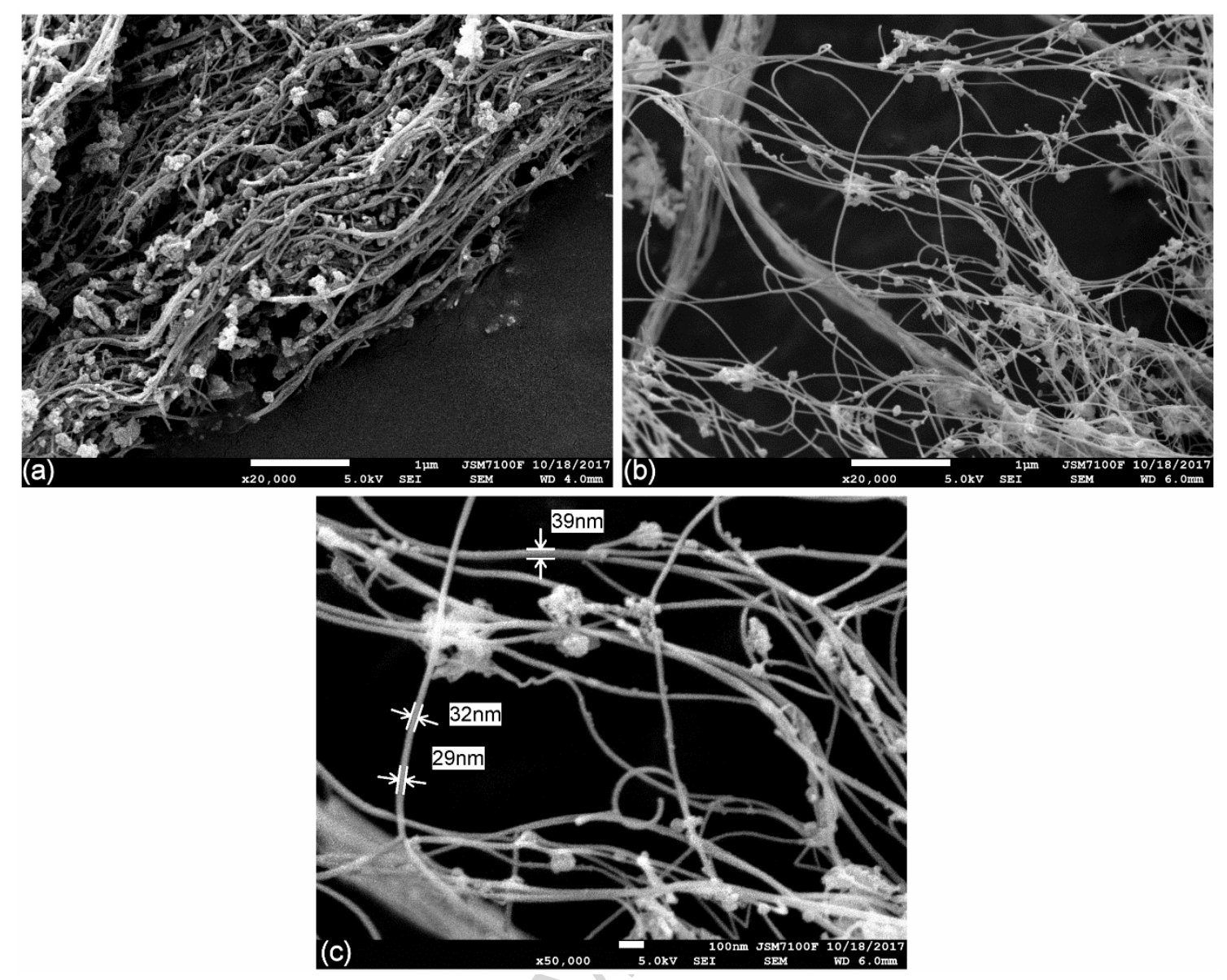

Figure 2. SEM pictures of BNNTs.

The XRD pattern of the BNNTs is shown in Figure 3. This figure shows the main diffraction peak at $25.9^{\circ}$ and two less pronounced peaks at about $46.0^{\circ}$ and $54.0^{\circ}$. These peaks can be assigned to the reflections of the planes (002), (101) and (004) of the hBN structure, respectively. A large d-spacing of the (002) planes of $3.3 \AA$ is observed that is very close to ideal value of $3.333 \AA$ for ordered hexagonal BN.

The true density of the BNNTs was determined by gas pycnometry. The cell and experimental device used were first calibrated with calibrated balls with known properties and a standard deviation of volume of $2.15 \%$ was reported. Next, experiments were performed at room temperature in two replicates with two different masses of sample, which were carefully weighed with a precision balance. For each 
replicate, density was an average of 6 measurements. Finally, a value of $1.3965 \mathrm{~g} / \mathrm{cm}^{3}$ was obtained, which agrees well with data previously reported [47].

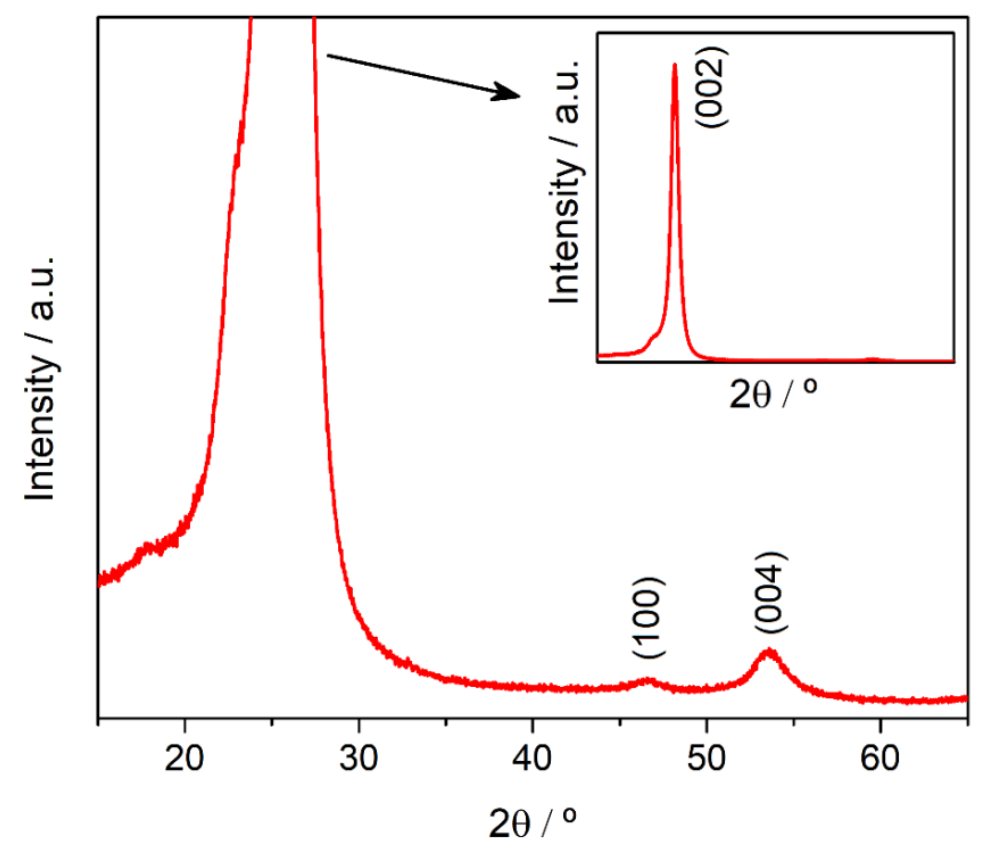

Figure 3. Powder XRD of BNNTs.

\subsection{Nanofluid characterization}

\subsubsection{Nanofluid stability}

Preparing stable nanofluids is the key to most nanofluid applications since their thermal properties are determined by the quality of the colloidal dispersion achieved. In this sense, nanofluid systems are considered to be stable when the concentration of nanoparticles in suspension and/or their size remain constant over time[48]. Nanofluids are dynamic systems, meaning nanomaterial in suspension tends to agglomerate due to attraction forces, while sedimentation can also occur. This has a negative effect on the stability and thermal properties of nanofluids[49]. Consequently, the analysis of the physical stability of nanofluids is of great interest and was therefore analysed using 
techniques such as UV-vis spectroscopy, dynamic light scattering to obtain the particle size, and $\zeta$ potential.

The sedimentation process in the five nanofluids was determined using UV-vis spectroscopy and by analysing the evolution of the extinction coefficient with time. Figure $4 \mathrm{a}$ shows the evolution of the extinction coefficient measured at $\lambda=400 \mathrm{~nm}$ for at least 25 days. For the measurements, the nanofluid with the highest concentration was diluted at a ratio of 1:5 (nanofluid:base fluid). At $\lambda=400 \mathrm{~nm}$, photonic absorption and light scattering processes occurred due to the presence of BNNTs in suspension, so the evolution of the extinction coefficient at this wavelength gives information about the presence of nanomaterial in the base fluid. The extinction coefficient of all the nanofluids decreased during the first few days, after which time it remained stable. Therefore, all the nanofluids became stable and could be promising for use as heat transfer fluids. Figure $4 \mathrm{~b}$ shows the plot of the extinction coefficient when the nanofluids reached physical stability versus the nominal mass concentration of BNNTs. A linear relationship is observed, indicating that the amount of nanomaterial incorporated into the base fluid leads to stable nanofluids and that the sedimentation process does not occur to a greater extent in any of the nanofluids. In turn, physical stability was also analysed from particle size measurements using the DLS technique. Figure $4 \mathrm{c}$ shows how the size of the particles in the nanofluids evolved over 25 days or more. Particle size measurements showed a unimodal distribution and all the values obtained were between 150 and $180 \mathrm{~nm}$. These values are higher than the nominal value reported from SEM, but agglomeration can occur in colloidal suspensions. Thus, these values show that all the nanofluids were highly stable, which is coherent with the results obtained from UV-vis spectroscopy. Moreover, the nanofluid with the lowest mass concentration showed the smallest particle size, while no differences were observed 
among the remaining nanofluids. The difference with regard to the nanofluid with lowest concentration was very slight. Finally, $\zeta$ potential of the nanofluids was measured, Figure $4 \mathrm{~d}$ showing the values obtained. These are also coherent with the results from UV-vis spectroscopy and particle size measurements; that is, the values remain stable over time. After the first few days, all the values obtained were between 25 and $-20 \mathrm{mV}$.

(a)

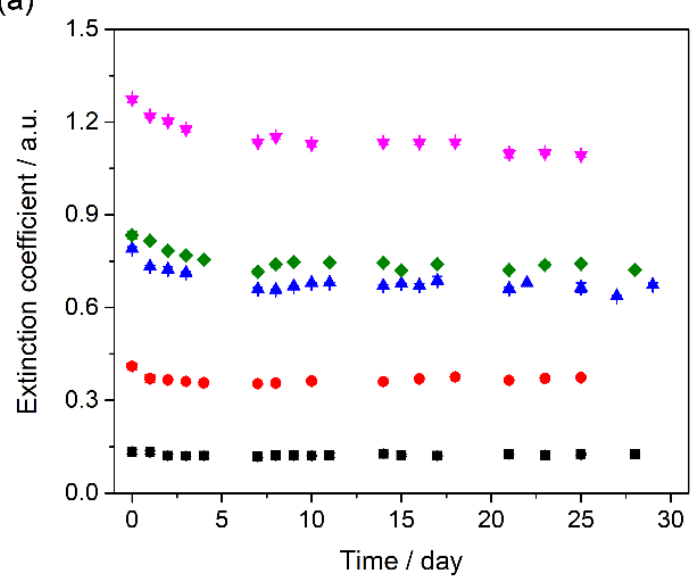

(c)

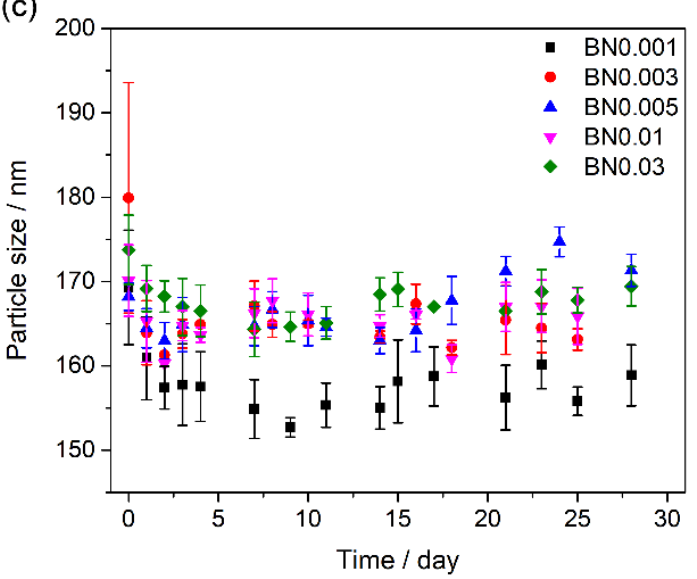

(b)

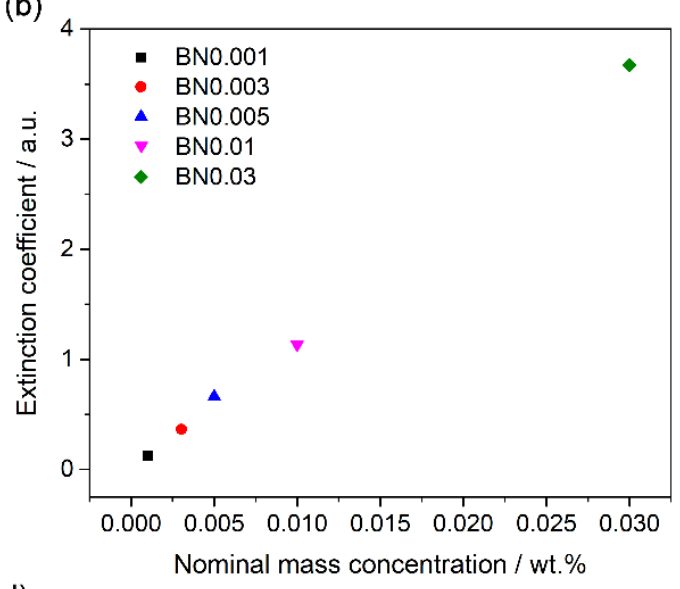

(d)

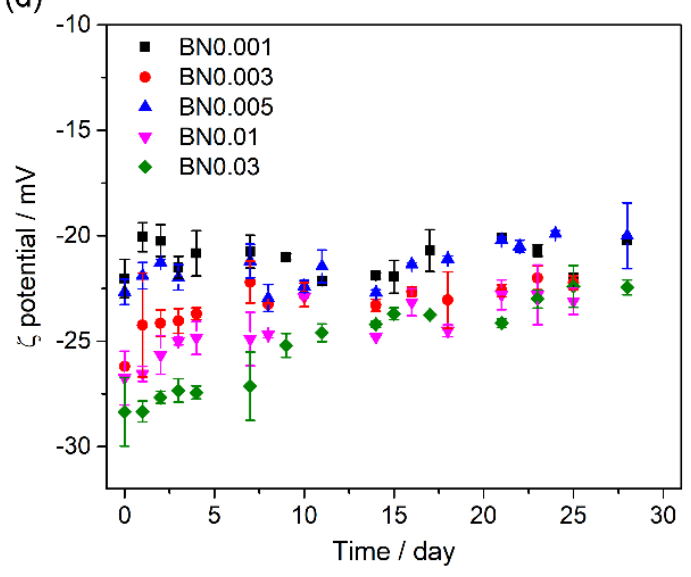

Figure 4. (a) Evolution of the extinction coefficient measured at $\lambda=400 \mathrm{~nm}$ with time.

(b) Extinction coefficient when nanofluids reached physical stability versus nominal BNNT mass concentration. (c) Particle size versus time. (d) $\zeta$ potential versus time for the nanofluids prepared. 
The density of nanofluids has been shown to affect the efficiency of the heat transfer fluid, studies reporting an increase in efficiency when density increases [43]. Consequently, density was measured when the nanofluids were stable. These values were also used to calculate the volume fraction of the nanofluids according to $\phi=$ $\left(\rho_{n f}-\rho_{b f}\right) /\left(\rho_{n t}-\rho_{b f}\right)$, where $\rho$ is the density and the subscripts $n f, b f$ and $n t$ refer to the nanofluid, base fluid and BN nanotubes. In this study, as noted above, the solution of Triton-X in water in the proportion defined in the Experimental section is considered the base fluid. The density of the nanofluids and base fluid was measured by pycnometry. The density of the BNNTs was measured using gas pycnometry with a value of $1396.5 \mathrm{~kg} \mathrm{~m}^{-3}$ obtained, as described above. Table 1 shows density and volume fraction values for the nanofluids, a slight increase in density with nanoparticle content being observed, as expected.

Table 1. Density and volume fraction values for the nanofluids prepared.

\begin{tabular}{c|c|c}
\hline wt.\% BNNTs & $\rho / \mathrm{kg} \mathrm{m}^{-3}$ & $\phi / \mathrm{vol} \%$ \\
\hline $0.0\left(\mathrm{H}_{2} \mathrm{O}+\right.$ Triton-X) & 998.4 & 0.000 \\
\hline 0.001 & 998.7 & 0.080 \\
\hline 0.003 & 998.9 & 0.126 \\
\hline 0.005 & 999.0 & 0.151 \\
\hline 0.01 & 999.2 & 0.206 \\
\hline 0.03 & 999.4 & 0.254 \\
\hline
\end{tabular}

\subsubsection{Surface tension measurements}

The surface tension (ST) of the base fluid and nanofluids was measured as described above. Knowing this property is of great importance in heat transfer systems, in particular those involving boiling heat transfer and condensation. The experimental uncertainty of measurements performed with this device was previously reported to be less than $1 \%$ [50]. Calibration of the device was also checked at $20^{\circ} \mathrm{C}$ with two pendant 
drop calibration gauges provided by the device manufacturer and a maximum relative deviation of $0.1 \%$ was obtained. In addition, the ST of distilled water (DW) was first measured in the same temperature range and the values were compared to Equation (2), established by [51]

$$
\gamma=235.8\left[\frac{647.15-T}{647.15}\right]^{1.256}\left[1-0.625\left(\frac{647.15-T}{647.15}\right)\right]
$$

where $\gamma$ is $\mathrm{ST}$ in $\mathrm{mN} / \mathrm{m}$ and $\mathrm{T}$ the temperature in Kelvin.

As mentioned above, the experimental equipment and procedure was first evaluated from the ST measurement of DW. The results are shown in Figure 5a. The figure shows that the ST of DW decreases with temperature as expected and that a very good agreement is achieved between experimental data and equation (1), with an absolute average deviation $\mathrm{AAD}=1.08 \%$. In addition, the experimental conditions at $20^{\circ} \mathrm{C}$ are not significantly affected when the drop is produced at ambient condition or within the temperature chamber. The ST of the base fluid is also reported in Figure 5a. It shows that the surface tension of DW is drastically reduced with the presence of surfactant, indicating that the surface tension of the base fluid is mainly governed by surfactant. This decrease in ST was about $44.5 \%$ and was not dependent on temperature. Consequently, the ST reduction rate of the base fluid with temperature was similar to that of water. Again, the ST of the base fluid was not modified by the experimental conditions at $20^{\circ} \mathrm{C}$.

The evolution of the ST of the nanofluids with both nanoparticle content and temperature is reported in Figure 5b. It shows that the nanofluid ST was weakly affected by the presence of any amount of nanoparticles, within the experimental uncertainty, and was mainly governed by the presence of surfactant. This is probably due to the low content considered in this study. As expected, the ST of the nanofluids also decreased with temperature with a trend similar that of the base fluid. Finally, as the ST of the 
nanofluids mainly decreased in the presence of surfactant, this could lead to increased heat flux in real systems [44].
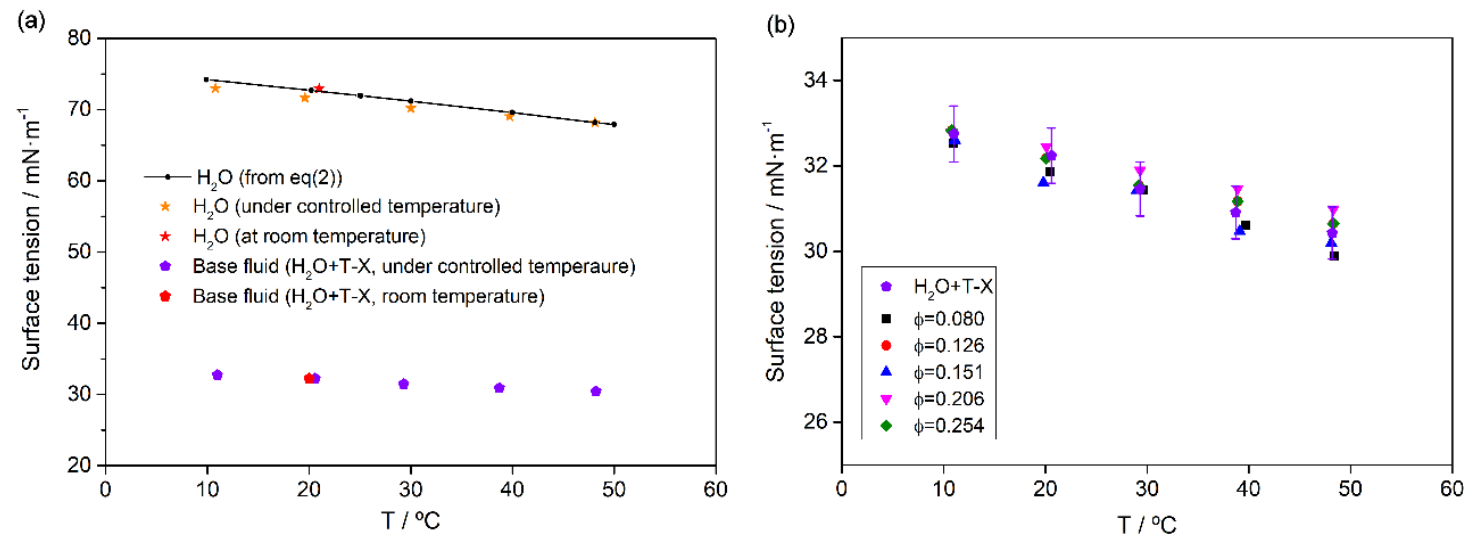

Figure 5. (a) Surface tension of DW and base fluid - Influence of temperature. (b) Surface tension of base fluid and nanofluids- Influence of temperature and nanoparticle content.

\subsubsection{Rheological properties}

Rheological measurements were performed in to determine how the nanoparticles affected the rheological behaviour of the base fluid. As expected, a Newtonian behaviour was reported for water for all tested temperatures and it was clear to see that water viscosity decreased with temperature, as shown in Figure 6. The viscosity data for water were favourably compared to values reported by [51] with an absolute average deviation $(\mathrm{AAD})=4.3 \%$ in the $10-50^{\circ} \mathrm{C}$ range. Flow curves of water at 10 and $40^{\circ} \mathrm{C}$ are also reported in Figure 7 to show the Newtonian behaviour. The shear flow behaviour of the base fluid at the same temperature is also reported. The results indicate that the base fluid also behaved in a Newtonian manner within the shear rate range investigated. Similar results were also obtained for other temperatures. It is also observed that the viscosity of base fluid was slightly higher than that of water, with an absolute average 
increase of $6.9 \%$ in the $10-40^{\circ} \mathrm{C}$ range, as illustrated by both Figures 6 and 7. Viscosity also decreased with temperature following a similar trend to water.

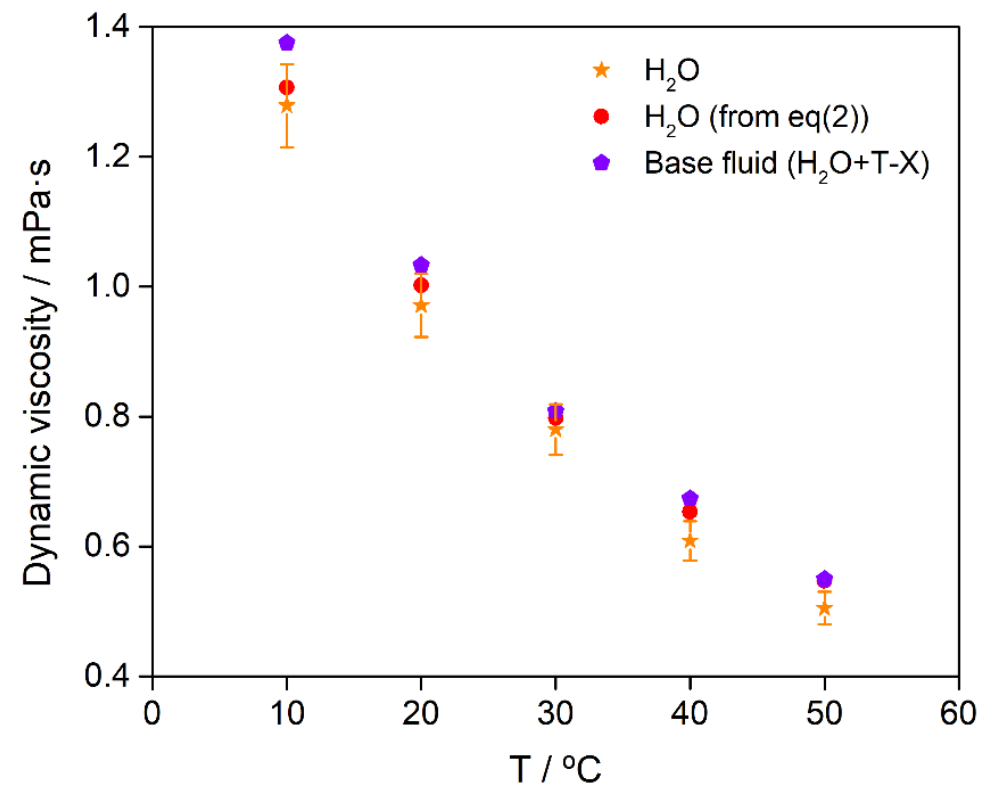

Figure 6. Viscosity data of water and base fluid.
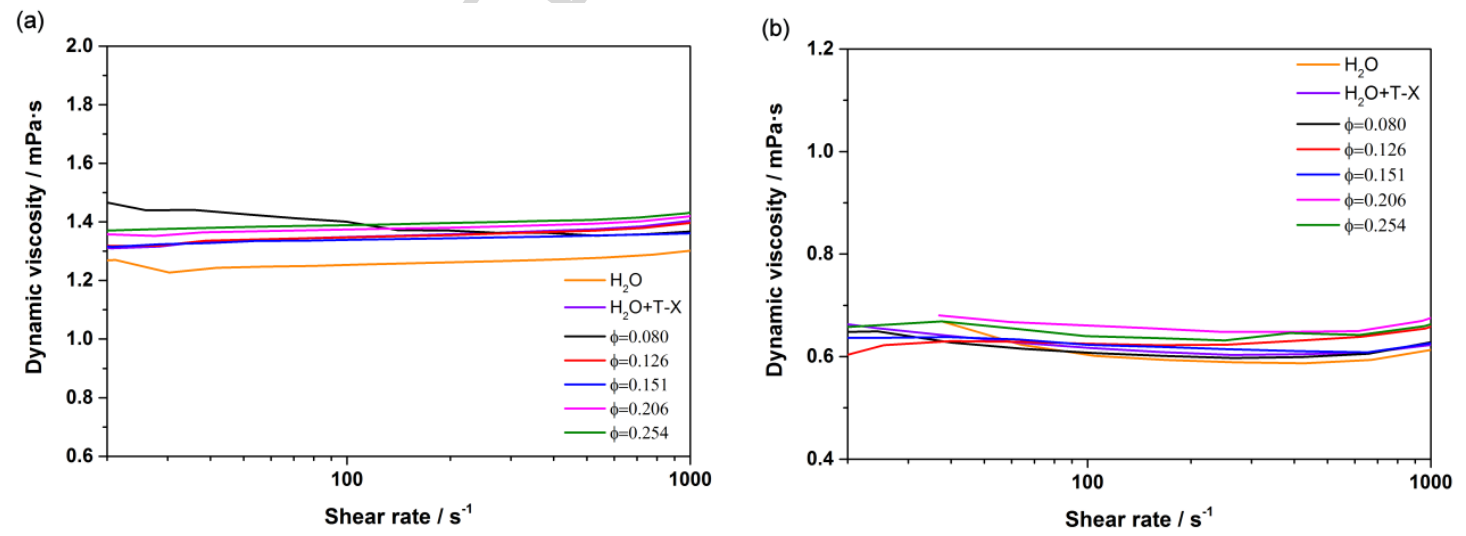

Figure 7. Viscosity data of water, base fluid and nanofluids in accordance with shear rate at $10^{\circ} \mathrm{C}(\mathrm{a})$ and $40^{\circ} \mathrm{C}(\mathrm{b})$. 
Finally, Figure 7 shows that the base fluid was only slightly affected by nanoparticle content as mainly Newtonian behaviour is maintained in the shear rate range investigated, within experimental uncertainty, with no significant increase in viscosity. This is evidenced by Figure 8 where the relative viscosity deviation of the nanofluids compared to the base fluid is plotted according to the nanoparticle content for all temperatures. The figure shows that the evolution of relative viscosity was within experimental uncertainty whatever the nanoparticle loading and temperatures (taking into consideration uncertainty of base fluid and nanofluid measurement).

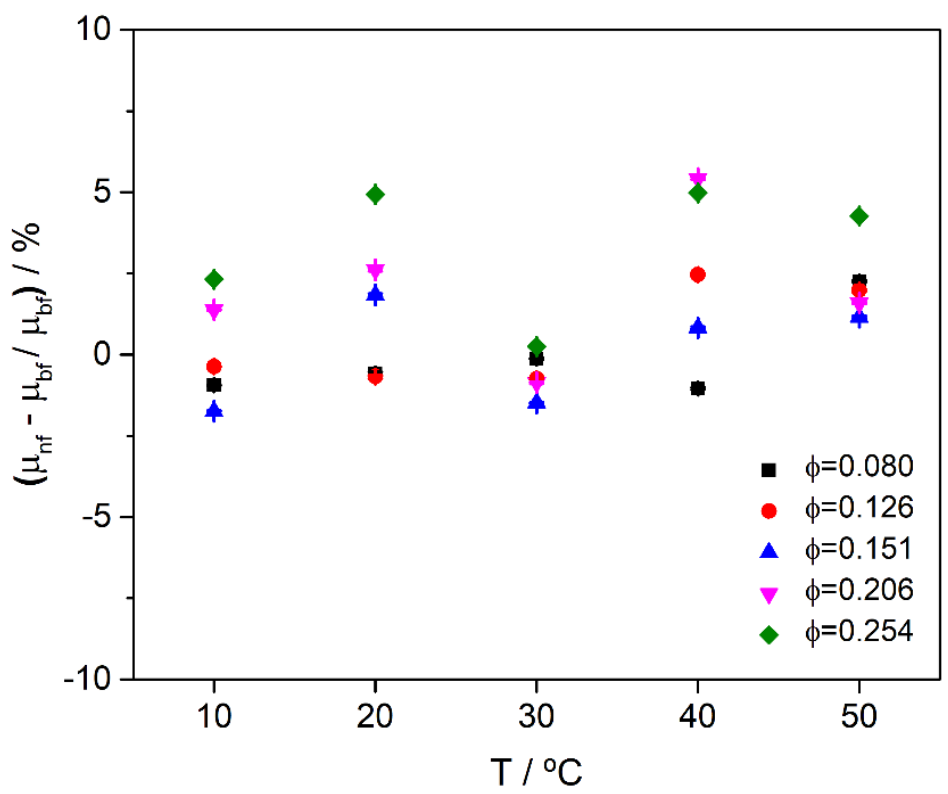

Figure 8. Relative viscosity deviation of nanofluids compared to base fluid according to nanoparticle content and temperature.

\subsubsection{Thermal properties}

The nanofluids were analysed to determine their isobaric specific heat and thermal conductivity. Isobaric specific heat has a vital role in the performance of heat transfer 
fluids and therefore the values of this property for the nanofluids prepared was measured between room temperature and $70{ }^{\circ} \mathrm{C}$. Figure 9 shows the values obtained for the nanofluids and also for the base fluid and for water with regard to temperature and volume fraction. The isobaric specific heat increased for all the nanofluids with regard to the base fluid and water, the nanofluids with higher volume fractions presenting the greatest increases. At $70{ }^{\circ} \mathrm{C}$ the isobaric specific heat increased by $8.3 \%$ and $8.0 \%$ with regard to water and the base fluid, respectively. The isobaric specific heat of solids is usually lower than that of fluids; thus, taking into account the "simple mixture rule", the values expected for nanofluids would be lower than those for the base fluid, as reported previously $[43,52,53]$. This model can be represented by a simple equation given as

$$
C_{P, n f}=\phi \cdot C_{P, n p}+(1-\phi) \cdot C_{P, b f}
$$

where $\phi$ is the volume fraction and $C_{P}$ is the isobaric specific heat, and the subscripts $n f$, $n p$ and $b f$ refer to the nanofluids, nanoparticles and base fluid, respectively [52]. The thermal equilibrium model is used to predict the values of isobaric specific heat, and usually fits the experimental values better. However, this model also predicts lower isobaric specific heat values for nanofluids due to the lower values for solids with regard to fluids [52]. Figure $9 \mathrm{~b}$ shows the values obtained for the nanofluids and the plot of the values generated using equation (3) and, as expected, the model did not give a good fit to the experimental values. However, some studies have reported different behaviour of isobaric specific heat; that is, an increase in the isobaric specific heat values for nanofluids with regard to the base fluid [9, 20, 54-56]; and nanofluids with higher isobaric specific heat values with regard to the base fluid but showing a wavelike behaviour with regard to the volume fraction [57]; or nanofluids showing isobaric 
specific heat values greater than the base fluid, but which decreases with the increase in volume fraction [58]. Furthermore, the interfacial free energy of solid-liquid is altered with suspended nanomaterials. Due to the higher specific surface area of nanomaterials, which depends on their morphology, their surface free energy has a greater proportion of the capacity of the system, which affects the isobaric specific heat. The surface free energy depends on the nature of the components of the system, their properties and the interactions between them, and therefore on the molecular-level structure. Thus, we feel it is very complicated to rationalize the behaviour of the $\mathrm{C}_{\mathrm{P}}$ for nanofluids at the present time. Therefore, the behaviour found in this study can be attributed to an internal structure forming inside the nanofluid that depends on the nature of the components $[9$, 54]. This structure is one of the heat storage modes related to the layers of liquid and surfactant molecules around the nanomaterial that constitute a solid-like layer with higher specific heat than the bulk liquid. Thus, an internal structure involving the water and surfactant molecules around the BNNTs may have been formed in the nanofluids, giving high isobaric specific heat values and making the nanofluids very stable, as shown above.

(a)

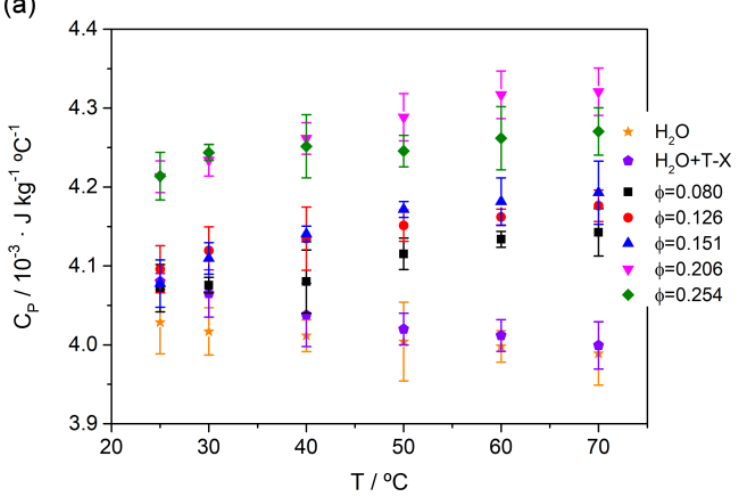

(b)

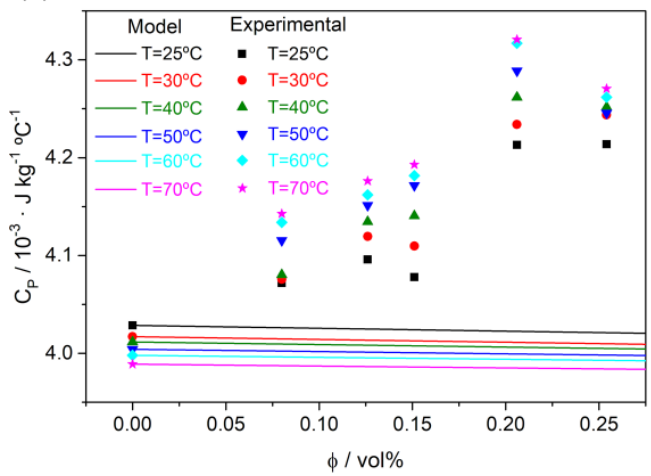

Figure 9. (a) Isobaric specific values of the nanofluids; (b) comparison with a simple model given in equation (3). 
An increase in thermal conductivity is known to lead to more efficient heat transfer [59], and the suspension of nanomaterials in a fluid increases its thermal conductivity $[17,19,20,60]$. Thus, the thermal conductivity of the nanofluids was measured at 30 , 50 and $70{ }^{\circ} \mathrm{C}$ following the procedure described above. Figure 10a shows the values obtained with regard to temperature and volume fraction. In all cases, thermal conductivity is seen to increase with temperature, meaning the nanofluids follow the same trend as the base fluid. Furthermore, the values for the nanofluids were higher than those of the base fluid and water. Figure $10 \mathrm{~b}$ shows the $\mathrm{k}_{\mathrm{nf}} / \mathrm{k}_{\mathrm{bf}}$ ratio with regard to temperature and the volume fraction. An increase of about $10 \%$ is observed for the two nanofluids with the highest volume fractions.
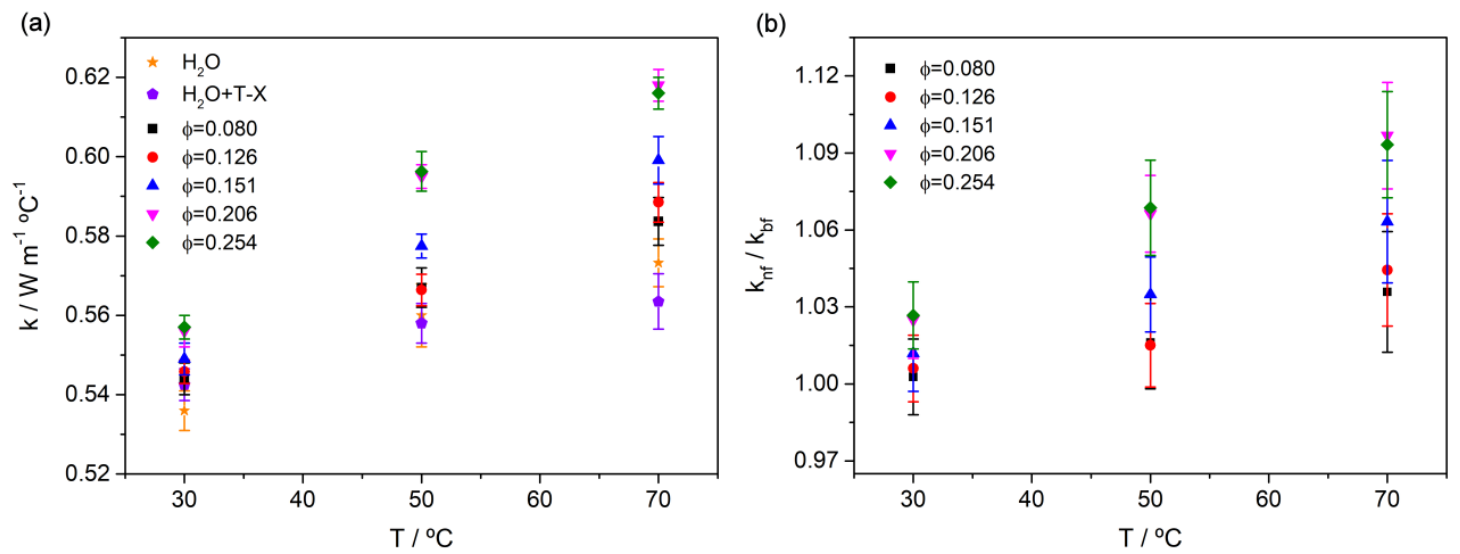

Figure 10. (a) Thermal conductivity values of the nanofluids; (b) thermal conductivity ratio between nanofluids and base fluid.

In turn, it is of interest to analyse the increase in thermal conductivity values using models that relate thermal conductivity with volume fraction. The first model reported with this aim was presented by Maxwell [61]: 


$$
\frac{k_{n f}}{k_{b f}}=\frac{k_{p}+2 k_{b f}+2\left(k_{p}-k_{b f}\right) \phi}{k_{p}+2 k_{b f}-\left(k_{p}-k_{b f}\right) \phi}
$$

where $k_{p}$ is the thermal conductivity of the BNNTs, that is $46 \mathrm{~W} \mathrm{~m}^{-1}{ }^{\circ} \mathrm{C}^{-1}$.[62] HamiltonCrosser $(\mathrm{H}-\mathrm{C})$ modified the Maxwell model to take into account the shape of the nanomaterial [63]:

$$
\frac{k_{n f}}{k_{b f}}=\frac{k_{p}+(n-1) k_{b f}+(n-1)\left(k_{p}-k_{b f}\right) \phi}{k_{p}+(n-1) k_{b f}-\left(k_{p}-k_{b f}\right) \phi}
$$

where $n$ is the shape factor, usually defined as $n=3 / \psi, \psi$ being the sphericity, which can be calculated from the dimensions of the nanomaterial. However, as the dimensions of the BNNTs were not well-known in this case, the H-C model cannot be used. Moreover, many models to predict the thermal conductivity of spherical nanoparticles can be found in the literature, but there are few specific models for nanofluids based on nanotubes. One of these is the Xue model [64]:

$$
\frac{k_{n f}}{k_{b f}}=\frac{1-\phi+2 \phi \frac{k_{p}}{k_{p}-k_{b f}} \ln \frac{k_{p}+k_{b f}}{2 k_{b f}}}{1-\phi+2 \phi \frac{k_{b f}}{k_{p}-k_{b f}} \ln \frac{k_{p}+k_{b f}}{2 k_{b f}}}
$$

where all the variables have been previously defined. Figure 11 shows the plot of the Maxwell model and the Xue model and the experimental results for comparison purposes at several temperatures. At $30^{\circ} \mathrm{C}$ and low volume fraction values, both models show values close to the experimental ones, but neither model predicts the experimental values very well. Typically, the experimental values are higher than those predicted by the models because they do not consider the interaction between the components of the nanofluid system. At high temperatures, the deviation is higher because the number of interactions increases. For example, the motion of particles in suspension can enhance the heat transport within the base fluid $[12,65]$. One of the reasons for the increase in heat transport and thermal conductivity postulated is the stochastic motions of the 
nanomaterial in suspension and the interactions between particles and the fluid molecules; that is, Brownian motion. Thus, assuming that this mechanism can be considered separately, the total effective thermal conductivity can be considered as the sum of the terms related to static conductivity and Brownian motion; that is, $k_{n f}=$ $k_{\text {static }}+k_{\text {brownian }}$. Thus, to take into account dynamic transport, Xuan et al. reported a model that includes the influence of viscosity, temperature and other properties of the base fluid and the nanoparticles, given by [65]

$$
k_{\text {brownian,Xuan }}=\frac{\rho_{p} \phi C_{P, b f}}{2} \sqrt{\frac{\kappa T}{3 \pi \mu r_{c}}}
$$

where $\rho_{p}$ is the density of BNNTs $\left(1396.6 \mathrm{~kg} \mathrm{~m}^{-3}\right), C_{P, b f}$ is the isobaric specific heat of the base fluid, $\kappa$ is the Boltzmann constant, $\mu$ the viscosity and $r_{c}$ is the mean gyration radius of the cluster. This value is estimated from the DLS measurements shown above when the nanofluids are considered stable. Also, Koo and Kleinstreuer introduced a new model considering the $\mathrm{H}-\mathrm{C}$ model and a contribution of Brownian motion[66]. This Brownian contribution is given by [66]

$$
k_{\text {brownian,Koo-Kleinstreuer }}=5 \times 10^{4} \beta \phi \rho_{b f} C_{P, b f} \sqrt{\frac{\kappa T}{\rho_{p} d_{p}}} f(T, \phi)
$$

where $d_{p}$ is the diameter of the cluster, also obtained from DLS measurements, as described above. $\beta$ and $f(T, \phi)$ can be fitted to experimental data. $\beta$ depends on the type of nanomaterial, and $f(T, \phi)$ is a function of the temperature and volume fraction. In this work, combinations of the Maxwell and Xue model for static conduction and the Brownian contribution reported by Koo and Kleinstreuer have been considered. Thus, Figure 11 shows the results of the application of the Maxwell and Xue models combined with the Xuan, and Koo and Kleinstreuer models for Brownian motion. At 30 ${ }^{\circ} \mathrm{C}$, the Maxwell and Xue models predict the experimental values at a low volume 
fraction. The values obtained using the Xuan model for Brownian motion were higher than the experimental values, so at low temperatures the Xuan model overestimates thermal conductivity values. At $50{ }^{\circ} \mathrm{C}$, the Maxwell and Xue models underestimate the experimental values in the whole volume fraction range. At this temperature, the Xuan model for Brownian motion predicts the experimental values well, as Figure 11b shows. At $70{ }^{\circ} \mathrm{C}$, the values predicted using the combination of the Maxwell and Xue models with the Xuan model for Brownian motion are underestimated with regard to the experimental ones. At the three temperatures studied, the Koo and Kleinstreuer model for Brownian motion with both the Maxwell and Xue models predicts the experimental values well, fitting the values of $\beta$ and $f(T, \phi)$, which are closer to those reported previously [67]. It can also be observed that $\beta$ does not change, which is coherent because, as stated above, $\beta$ depends on the kind of nanomaterial and the same type was used in all the nanofluids. In turn, $f(T, \phi)$ increased linearly with temperature, as the models predict [68]. The values of $\beta$ and $f(T, \phi)$ are shown in Figure 11d. Thus, the contribution of Brownian motion is clearly observed, and this contribution increases with temperature. 
(a)

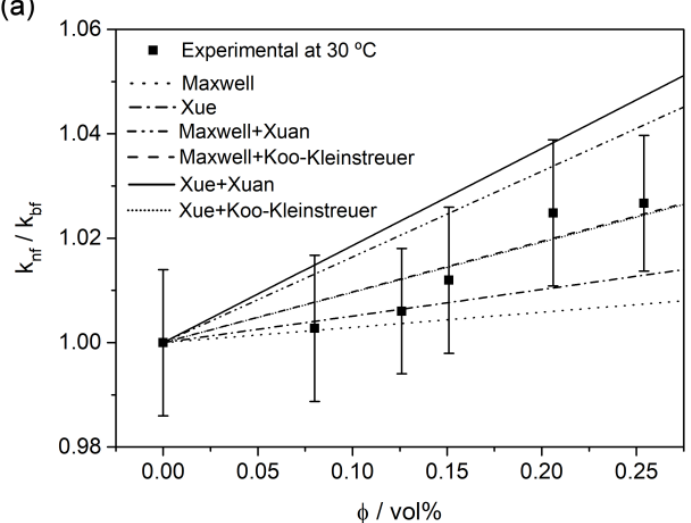

(c)

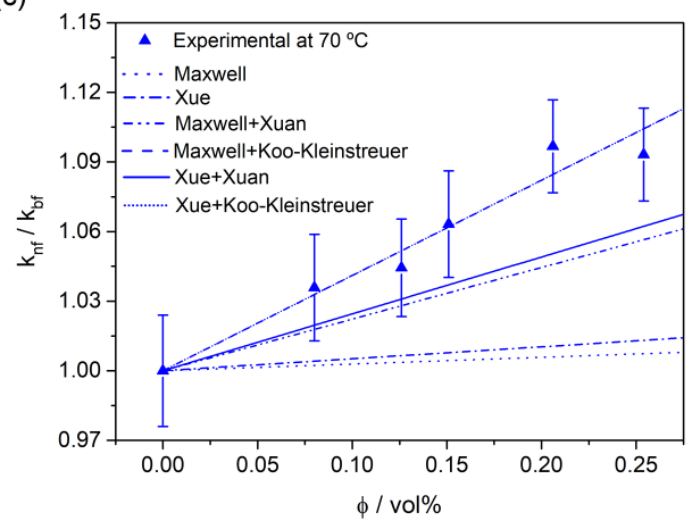

(b)

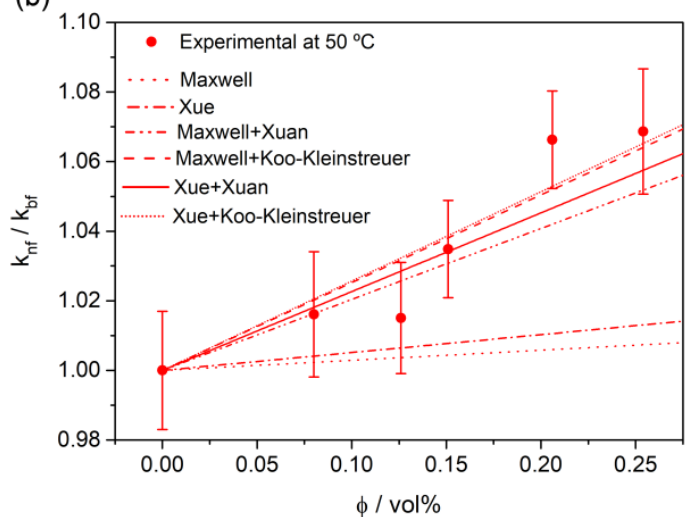

(d)

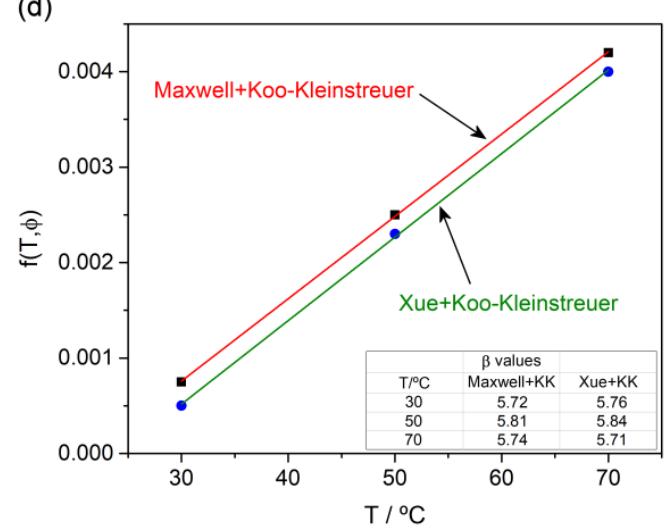

Figure 11. Thermal conductivity values for the nanofluids prepared and the plots of several theoretical models for thermal conductivity at $30{ }^{\circ} \mathrm{C}(\mathrm{a}), 50{ }^{\circ} \mathrm{C}$ (b) and $70{ }^{\circ} \mathrm{C}(\mathrm{c})$. (d) Parameters values obtained with the Koo and Kleinstreuer model.

\section{Conclusions}

This study presents an analysis of nanofluids based on BNNTs. An aqueous solution of Triton X-100, which acts as a surfactant, was used as a base fluid. The stability, surface tension, rheological and thermal properties of the nanofluids were studied.

For all nanofluids prepared, the extinction coefficient obtained from UV-vis spectroscopy decreased during the first few days, after which it remained stable. Particle size measurements showed a characteristic unimodal distribution, all values ranging between 150 and $180 \mathrm{~nm}$ and presenting high stability in all cases. Moreover, the $\zeta$ potential values, which were stable over time, were coherent with those obtained from 
UV-vis spectroscopy and particle size measurements. Therefore, all the nanofluids prepared reached a stable condition and may be promising for use as heat transfer fluids. Furthermore, the evolution of the surface tension of the nanofluids according to their nanoparticle content and temperature was analysed. Water surface tension was weakly affected by the presence of nanoparticles whatever the content and was mainly governed by the presence of Triton X-100 as the surfactant. This is probably due to the low nanotube content considered in this study. As expected, the surface tension of the nanofluids also decreased with temperature following a trend similar to that of the base fluid because the values are governed by the surfactant.

In addition, rheological properties were measured. The results indicated that the base fluid behaved in Newtonian manner within the shear range investigated. In turn, the nanofluids showed a mainly Newtonian behaviour with no significant increase in viscosity.

Furthermore, thermal properties, such as isobaric specific heat and thermal conductivity, were measured. The isobaric specific heat increased by $8.3 \%$ and $8.0 \%$ at $70{ }^{\circ} \mathrm{C}$ with regard to water and the base fluid, respectively. Also, the thermal conductivity of the nanofluids increased with regard to the base fluid and water, this increase reaching about $10 \%$ for the two nanofluids with the highest volume fraction. In order to understand the heat transport mechanism, several models of thermal conductivity were analysed. The contribution of Brownian motion was clearly observed, this contribution increasing with temperature.

So, from a practical perspective, the results obtained are interesting because while the thermal properties of the fluids improved with nanoparticle content, their rheological behaviour did not change. Consequently, use of nanofluids cannot modify pressure drop 
and pumping power in real situations. Therefore, the nanofluids prepared could be a promising alternative to the typical HTF used. 


\section{Acknowledgements}

Roberto Gómez-Villarejo acknowledges EU COST for the STSM grant ref. COSTSTSM-CA15119-37968 linked to the Cost Action “Overcoming Barriers To Nanofluids Market Uptake (NANOUPTAKE)".

P. Estellé acknowledges the European Union through the European Regional Development Fund (ERDF), the Ministry of Higher Education and Research, the French region of Brittany and Rennes Métropole for the financial support related to surface tension and gas pycnometer devices used in this study. He also acknowledges Francis Gouttefangeas from CMEBA, Université Rennes 1 and Mathieu Pasturel from the Institut des Sciences Chimiques de Rennes, Université Rennes 1 for performing respectively the SEM and XRD characterization.

J. Navas acknowledges the Ministerio de Economia y Competitividad (MINECO) of the Spanish Government for funding under Grant No. ENE2014-58085-R, for the financial support related to the isobaric specific heat and thermal conductivity measurements, which were performed using equipment acquired under Grant No. UNCA15-CE-2945. 


\section{References}

[1] S.U.S. Choi, J.A. Eastman, Enhancing thermal conductivity of fluids with nanoparticles, in: INternational Mechanical Engineering Congress and Exhibition, Argonne National Lab., USA, 1995, pp. 99-105.

[2] O. Mahian, L. Kolsi, M. Amani, P. Estellé, G. Ahmadi, C. Kleinstreuer, J.S. Marshall, M. Siavashi, R.A. Taylor, H. Niazmand, S. Wongwises, T. Hayat, A. Kolanjiyil, I. Pop, Recent Advances in Modeling and Simulation of Nanofluid FlowsPart I: Fundamental and Theory, Physics Reports, (2018).

[3] O. Mahian, L. Kolsi, M. Amani, P. Estellé, P. Ahmad, C. Kleinstreuer, J.S. Marshall, R.A. Taylor, E. Abu-Nada, S. Rashidi, H. Niazmand, S. Wongwises, T. Hayat, A. Kasaeian, I. Pop, Recent Advances in Modeling and Simulation of Nanofluid Flows-Part II: Applications, Physics Reports, (2018).

[4] N.A.C. Sidik, M.N.A.W.M. Yazid, R. Mamat, A review on the application of nanofluids in vehicle engine cooling system, Int Commun Heat Mass, 68 (2015) 85-90.

[5] S. Kadri, R. Mehdaoui, M. Elmir, A vertical magneto-convection in square cavity containing a al2o3+water nanofluid: cooling of electronic compounds, Enrgy Proced, 18 (2012) 724-732.

[6] A. Yasinskiy, J. Navas, T. Aguilar, R. Alcantara, J.J. Gallardo, A. SanchezCoronilla, E.I. Martin, D. De Los Santos, C. Fernandez-Lorenzo, Dramatically enhanced thermal properties for TiO2-based nanofluids for being used as heat transfer fluids in concentrating solar power plants, Renew Energ, 119 (2018) 809-819.

[7] J.M. Wu, J.Y. Zhao, A review of nanofluid heat transfer and critical heat flux enhancement-Research gap to engineering application, Prog Nucl Energ, 66 (2013) 1324.

[8] J. Fal, O. Mahian, G. Zyla, Nanofluids in the Service of High Voltage Transformers: Breakdown Properties of Transformer Oils with Nanoparticles, a Review, Energies, 11 (2018) 2942.

[9] D. Shin, D. Banerjee, Enhanced Specific Heat Capacity of Nanomaterials Synthesized by Dispersing Silica Nanoparticles in Eutectic Mixtures, J Heat Trans-T Asme, 135(3) (2013) 032801.

[10] S.Z. Heris, M.A. Razbani, P. Estelle, O. Mahian, Rheological Behavior of ZincOxide Nanolubricants, J Disper Sci Technol, 36(8) (2015) 1073-1079.

[11] T. Yiamsawas, A.S. Dalkilic, O. Mahian, S. Wongwises, Measurement and Correlation of the Viscosity of Water-Based Al2O3 and $\mathrm{TiO} 2$ Nanofluids in High Temperatures and Comparisons with Literature Reports, J Disper Sci Technol, 34(12) (2013) 1697-1703.

[12] Y. Gao, H. Wang, A.P. Sasmito, A.S. Mujumdar, Measurement and modeling of thermal conductivity of graphene nanoplatelet water and ethylene glycol base nanofluids, Int J Heat Mass Tran, 123 (2018) 97-109.

[13] B. Ilhan, H. Erturk, Experimental characterization of laminar forced convection of hBN-water nanofluid in circular pipe, Int J Heat Mass Tran, 111 (2017) 500-507.

[14] G. Zyla, J. Fal, J. Traciak, M. Gizowska, K. Perkowski, Huge thermal conductivity enhancement in boron nitride - ethylene glycol nanofluids, Mater Chem Phys, 180 (2016) 250-255.

[15] O. Mahian, A. Kianifar, S. Wongwises, Dispersion of ZnO Nanoparticles in a Mixture of Ethylene Glycol-Water, Exploration of Temperature-Dependent Density, and Sensitivity Analysis, J Clust Sci, 24(4) (2013) 1103-1114.

[16] S.A. Angayarkanni, J. Philip, Review on thermal properties of nanofluids: Recent developments, Adv Colloid Interfac, 225 (2015) 146-176. 
[17] S. Lee, S.U.S. Choi, S. Li, J.A. Eastman, Measuring thermal conductivity of fluids containing oxide nanoparticles, J Heat Trans-T Asme, 121(2) (1999) 280-289.

[18] O. Mahian, A. Kianifar, S.Z. Heris, S. Wongwises, Natural convection of silica nanofluids in square and triangular enclosures: Theoretical and experimental study, Int J Heat Mass Tran, 99 (2016) 792-804.

[19] R. Gomez-Villarejo, E.I. Martín, J. Navas, A. Sánchez-Coronilla, T. Aguilar, J.J. Gallardo, R. Alcántara, D.M. De los Santos, I. Carrillo-Berdugo, C. Fernández-Lorenzo, Ag-based nanofluidic system to enhance heat transfer fluids for concentrating solar power: Nano-level insights, Applied Energy, 194 (2017) 19-29.

[20] J. Navas, A. Sánchez-Coronilla, E.I. Martín, M. Teruel, J.J. Gallardo, T. Aguilar, R. Gómez-Villarejo, R. Alcántara, C. Fernández-Lorenzo, J.C. Piñero, J. MartínCalleja, On the enhancement of heat transfer fluid for concentrating solar power using $\mathrm{Cu}$ and Ni nanofluids: An experimental and molecular dynamics study, Nano Energy, 27 (2016) 213-224.

[21] T. Ishii, T. Sato, Y. Sekikawa, M. Iwata, Growth of Whiskers of Hexagonal BoronNitride, J Cryst Growth, 52(Apr) (1981) 285-289.

[22] N.G. Chopra, R.J. Luyken, K. Cherrey, V.H. Crespi, M.L. Cohen, S.G. Louie, A. Zettl, Boron-Nitride Nanotubes, Science, 269(5226) (1995) 966-967.

[23] D. Golberg, Y. Bando, M. Eremets, K. Takemura, K. Kurashima, H. Yusa, Nanotubes in boron nitride laser heated at high pressure, Appl Phys Lett, 69(14) (1996) 2045-2047.

[24] O.R. Lourie, C.R. Jones, B.M. Bartlett, P.C. Gibbons, R.S. Ruoff, W.E. Buhro, CVD growth of boron nitride nanotubes, Chem Mater, 12(7) (2000) 1808-+.

[25] W.Q. Han, Y. Bando, K. Kurashima, T. Sato, Synthesis of boron nitride nanotubes from carbon nanotubes by a substitution reaction, Appl Phys Lett, 73(21) (1998) 30853087.

[26] Q. Huang, Y.S. Bando, X. Xu, T. Nishimura, C.Y. Zhi, C.C. Tang, F.F. Xu, L. Gao, D. Golberg, Enhancing superplasticity of engineering ceramics by introducing BN nanotubes, Nanotechnology, 18(48) (2007).

[27] G. Mpourmpakis, G.E. Froudakis, Why boron nitride nanotubes are preferable to carbon nanotubes for hydrogen storage? An ab initio theoretical study, Catal Today, 120(3-4) (2007) 341-345.

[28] A. Nag, K. Raidongia, K.P.S.S. Hembram, R. Datta, U.V. Waghmare, C.N.R. Rao, Graphene Analogues of BN: Novel Synthesis and Properties, Acs Nano, 4(3) (2010) 1539-1544.

[29] H.B. Zeng, C.Y. Zhi, Z.H. Zhang, X.L. Wei, X.B. Wang, W.L. Guo, Y. Bando, D. Golberg, "White Graphenes": Boron Nitride Nanoribbons via Boron Nitride Nanotube Unwrapping, Nano Lett, 10(12) (2010) 5049-5055.

[30] C.C. Tang, Y. Bando, Y. Huang, C.Y. Zhi, D. Golberg, Synthetic Routes and Formation Mechanisms of Spherical Boron Nitride Nanoparticles, Adv Funct Mater, 18(22) (2008) 3653-3661.

[31] C.H. Lee, S. Bhandari, B. Tiwari, N. Yapici, D.Y. Zhang, Y.K. Yap, Boron Nitride Nanotubes: Recent Advances in Their Synthesis, Functionalization, and Applications, Molecules, 21(7) (2016).

[32] Z.G. Chen, J. Zou, G. Liu, F. Li, Y. Wang, L.Z. Wang, X.L. Yuan, T. Sekiguchi, H.M. Cheng, G.Q. Lu, Novel Boron Nitride Hollow Nanoribbons, Acs Nano, 2(10) (2008) 2183-2191.

[33] W. Bauhofer, J.Z. Kovacs, A review and analysis of electrical percolation in carbon nanotube polymer composites, Compos Sci Technol, 69(10) (2009) 1486-1498. 
[34] R. Zhang, A. Dowden, H. Deng, M. Baxendale, T. Peijs, Conductive network formation in the melt of carbon nanotube/thermoplastic polyurethane composite, Compos Sci Technol, 69(10) (2009) 1499-1504.

[35] J. Yu, L. Qin, Y.F. Hao, S. Kuang, X.D. Bai, Y.M. Chong, W.J. Zhang, E. Wang, Vertically Aligned Boron Nitride Nanosheets: Chemical Vapor Synthesis, Ultraviolet Light Emission, and Superhydrophobicity, Acs Nano, 4(1) (2010) 414-422.

[36] F.M. Abbasi, M. Gul, S.A. Shehzad, Hall effects on peristalsis of boron nitrideethylene glycol nanofluid with temperature dependent thermal conductivity, Physica E, 99 (2018) 275-284.

[37] J. Fal, M. Cholewa, M. Gizowska, A. Witek, G. Zyla, Dielectric Properties of Boron Nitride-Ethylene Glycol (BN-EG) Nanofluids, J Electron Mater, 46(2) (2017) 856-865.

[38] B. Ilhan, M. Kurt, H. Erturk, Experimental investigation of heat transfer enhancement and viscosity change of hBN nanofluids, Exp Therm Fluid Sci, 77 (2016) 272-283.

[39] http://www.tekna.com/boron-nitride-nanotubes - brochures, in, 2018.

[40] Y.J. Li, J.E. Zhou, S. Tung, E. Schneider, S.Q. Xi, A review on development of nanofluid preparation and characterization, Powder Technol, 196(2) (2009) 89-101.

[41] W.S. Sarsam, A. Amiri, M.N.M. Zubir, H. Yarmand, S.N. Kazi, A. Badarudin, Stability and thermophysical properties of water-based nanofluids containing triethanolamine-treated graphene nanoplatelets with different specific surface areas, Colloid Surface A, 500 (2016) 17-31.

[42] R.C. Murdock, L. Braydich-Stolle, A.M. Schrand, J.J. Schlager, S.M. Hussain, Characterization of nanomaterial dispersion in solution prior to In vitro exposure using dynamic light scattering technique, Toxicol Sci, 101(2) (2008) 239-253.

[43] M. Chandrasekar, S. Suresh, T. Senthilkumar, Mechanisms proposed through experimental investigations on thermophysical properties and forced convective heat transfer characteristics of various nanofluids - A review, Renew Sust Energ Rev, 16(6) (2012) 3917-3938.

[44] P. Estelle, D. Cabaleiro, G. Zyla, L. Lugo, S.M.S. Murshed, Current trends in surface tension and wetting behavior of nanofluids, Renew Sust Energ Rev, 94 (2018) 931-944.

[45] D. Cabaleiro, P. Estellé, H. Navas, A. Desforges, B. Vigolo, Dynamic viscosity and surface tension of stable graphene oxide and reduced graphene oxide aqueous nanofluids, Journal of Nanofluids, Accepted for publication (2018).

[46] S. Halelfadl, P. Estelle, B. Aladag, N. Doner, T. Mare, Viscosity of carbon nanotubes water-based nanofluids: Influence of concentration and temperature, Int $\mathrm{J}$ Therm Sci, 71 (2013) 111-117.

[47] C.Y. Zhi, Y. Bando, C.C. Tang, D. Golberg, Specific heat capacity and density of multi-walled boron nitride nanotubes by chemical vapor deposition, Solid State Commun, 151(2) (2011) 183-186.

[48] W. Yu, H.Q. Xie, A Review on Nanofluids: Preparation, Stability Mechanisms, and Applications, J Nanomater, (2012).

[49] S. Chakraborty, I. Sarkar, K. Haldar, S.K. Pal, S. Chakraborty, Synthesis of Cu-Al layered double hydroxide nanofluid and characterization of its thermal properties, Appl Clay Sci, 107 (2015) 98-108.

[50] G. Zyla, J. Fal, P. Estelle, Thermophysical and dielectric profiles of ethylene glycol based titanium nitride (TiN-EG) nanofluids with various size of particles, Int $\mathbf{J}$ Heat Mass Tran, 113 (2017) 1189-1199. 
[51] N.B. Vargaftik, B.N. Volkov, L.D. Voljak, International Tables of the SurfaceTension of Water, J Phys Chem Ref Data, 12(3) (1983) 817-820.

[52] D. Cabaleiro, C. Gracia-Fernandez, J.L. Legido, L. Lugo, Specific heat of metal oxide nanofluids at high concentrations for heat transfer, Int J Heat Mass Tran, 88 (2015) 872-879.

[53] N.S.S. Mousavi, S. Kumar, Effective heat capacity of ferrofluids - Analytical approach, Int J Therm Sci, 84 (2014) 267-274.

[54] D. Shin, D. Banerjee, Specific heat of nanofluids synthesized by dispersing alumina nanoparticles in alkali salt eutectic, Int J Heat Mass Tran, 74 (2014) 210-214.

[55] I.C. Nelson, D. Banerjee, R. Ponnappan, Flow Loop Experiments Using Polyalphaolefin Nanofluids, J Thermophys Heat Tr, 23(4) (2009) 752-761.

[56] R.S. Vajjha, D.K. Das, Specific Heat Measurement of Three Nanofluids and Development of New Correlations, J Heat Trans-T Asme, 131(7) (2009).

[57] S. Sonawane, K. Patankar, A. Fogla, B. Puranik, U. Bhandarkar, S.S. Kumar, An experimental investigation of thermo-physical properties and heat transfer performance of Al2O3-Aviation Turbine Fuel nanofluids, Appl Therm Eng, 31(14-15) (2011) 28412849.

[58] V. Kumaresan, R. Velraj, Experimental investigation of the thermo-physical properties of water-ethylene glycol mixture based CNT nanofluids, Thermochim Acta, 545 (2012) 180-186.

[59] E.V. Timofeeva, W.H. Yu, D.M. France, D. Singh, J.L. Routbort, Nanofluids for heat transfer: an engineering approach, Nanoscale Res Lett, 6 (2011) 182.

[60] T. Aguilar, J. Navas, A. Sanchez-Coronilla, E.I. Martin, J.J. Gallardo, P. MartinezMerino, R. Gomez-Villarejo, J.C. Pinero, R. Alcantara, C. Fernandez-Lorenzo, Investigation of enhanced thermal properties in NiO-based nanofluids for concentrating solar power applications: A molecular dynamics and experimental analysis, Applied Energy, 211 (2018) 677-688.

[61] J.C. Maxwell, A treatise on electricity and magnetism, 3rd ed., Oxford University Press, London, 1892.

[62] C.C. Tang, Y. Bando, C.H. Liu, S.S. Fan, J. Zhang, X.X. Ding, D. Golberg, Thermal conductivity of nanostructured boron nitride materials, J Phys Chem B, 110(21) (2006) 10354-10357.

[63] R.L. Hamilton, O.K. Crosser, Thermal Conductivity of Heterogeneous 2Component Systems, Ind Eng Chem Fund, 1(3) (1962) 187-\&.

[64] Q.Z. Xue, Model for thermal conductivity of carbon nanotube-based composites, Physica B, 368(1-4) (2005) 302-307.

[65] Y.M. Xuan, Q. Li, W.F. Hu, Aggregation structure and thermal conductivity of nanofluids, Aiche J, 49(4) (2003) 1038-1043.

[66] J. Koo, C. Kleinstreuer, A new thermal conductivity model for nanofluids, J Nanopart Res, 6(6) (2004) 577-588.

[67] R.S. Vajjha, D.K. Das, Experimental determination of thermal conductivity of three nanofluids and development of new correlations, Int J Heat Mass Tran, 52(21-22) (2009) 4675-4682.

[68] R.S. Vajjha, D.K. Das, A review and analysis on influence of temperature and concentration of nanofluids on thermophysical properties, heat transfer and pumping power, Int J Heat Mass Tran, 55(15-16) (2012) 4063-4078. 


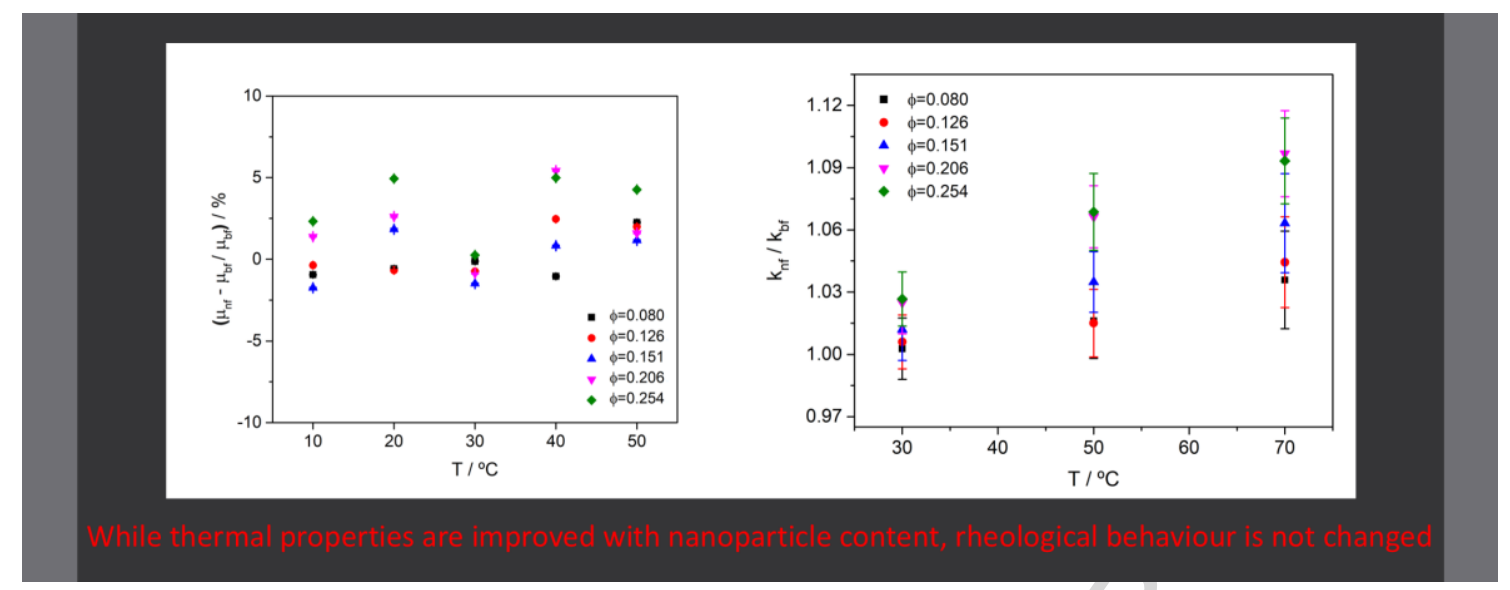

Graphical abstract 


\section{Highlights}

Stable nanofluids based on boron nitride nanotubes were prepared and analysed Isobaric specific heat increased by $8 \%$ and thermal conductivity by $10 \%$

Newtonian behaviour was found for nanofluids with no significant increase in viscosity Surface tension was mainly governed by the presence of Triton X-100 as surfactant Rheological behaviour is not changed with nanoparticle content 